\title{
A Model for the Interaction Between Business And SCIEnCE: The Risk Prediction Initiative at THE Bermuda Biological Station fOR Research
}

\author{
By Anthony H. Knap and Anthony F. Michaels
}

$\mathrm{T}$ HE Bermlda Biological Station for Research (BBSR) was established in 1903 and since then has been carrying out longterm research on the ocean and atmosphere. In response to the more recent societal interests in the interaction between environmental changes and society, the BBSR established the Atlantic Global Change Institute (AGCI) to look at the human dimensions of climate change.

Somewhat by accident, during discussions with potential donors for an ongoing BBSR endowment fund-raising drive, the question was raised of how the insurance industry analyzes the effects of a changing climate on their business. The obvious needs of this community led to the establishment in 1994 of the the Risk Prediction Initiative (RPI). This is one of the first programs to facilitate communication and collaboration between science and the global insurance industry, and, in many ways. it may be a model for similar kinds of programs with other industries.

Current RPI efforts focus on building bridges between the climate science and global insurance and reinsurance communities. This focus builds on the inherently similar interests of the two groups. While scientists continue to increase their ability to issue accurate climate forecasts months to years in advance, insurers explore ways to use those forecasts to help them

Anthony H. Knap. Anthony F. Michaels, Bermuda Biological Station for Research. St. Georges, Bermuda GE 01 .

Anne Arquit Niederberger, editor, International Policy Issues column. Forum for Climate and Global Change. Swiss Academy of Sciences, Baerenplatz 2. CH-3011 Bern. Switzerland. Internet: arquit@sanw.unibe.ch. assess and manage climate-related risks. The climate feature of most immediate interest is the control of the number of landfalling tropical cyclones each year and each decade. The unusually active 1995 hurricane season highlighted the value of the RPI. The 19 tropical storms, 11 hurricanes, and 4 intense (category 3 , 4 , or 5 storms with wind gusts $>110$ mph) hurricanes that formed in the Atlantic killed 121 people and caused $\$ 7.7$ billion of damage in the United States and Caribbean. This elevated level of activity had been forecast by climate scientists like Dr. Bill Gray, but the insurance industry was ill prepared to respond to these forecasts, in large part because of their lack of understanding of what the science community had to offer.

While the interests of climate scientists and insurers dovetail closely, differences in culture and tradition have precluded effective communication between the two groups. During the first full year of the programme in 1995, the RPI began to link these traditionally separate groups via direct meetings, workshops, and a home page on the World Wide Web (http://www.bbsr.edu/agcihome/rpi/rpihome.html). The goal of these RPI activities is to transfer effectively climate information and forecasts from scientists to insurers, help climate scientists recognize research that is relevant to insurers, increase insurers' appreciation for the utility of climate science, and investigate how insurers might best use climate forecasts to help them assess and manage the risks that catastrophic weather events pose. BBSR's proximity to Bermuda's large community of insurers and reinsurers makes it an ideal epicenter for the RPI.
Sponsorship of the RPI increased dramatically during 1995. The five founding insurance and reinsurance companies (Mid Ocean Re. Cat Ltd. Chubb Group. General Re, and Renaissance Reinsurance) were joined in the second half of 1995 by eight others (Tillinghast-Towers Perrin, ACE Ltd., Zurich/Centre Re, EXEL Ltd.. Terra Nova Reinsurance. AON Corporation, Employers Re, and American International Group), providing a research and education budget of over $\$ 1$ million per year.

Increased interest in the RPI also came via the Climate Prediction and Insurance Risk Conference held at Bermuda's Marriot Castle Harbour Resort in early November, 1995. This meeting was presented by BBSR's Atlantic Global Change Institute and sponsored by Cat Ltd., a Bermuda-based catastrophe reinsurance company and RPI sponsor. The conference attracted $>150$ participants from around the world and encouraged scientists and insurers to exchange ideas and explore their common ground. It featured three days of presentations and small group discussions in which leading climate scientists from the United States and Europe conversed with an international group of insurers. Climate scientists explained how the global climate system works, how human activities affect climate, and the strengths and weaknesses of current forecasting techniques. Insurers discussed how they might use climate forecasts to modify business practice and how the use of forecasts might provide novel opportunities within the insurance industry. Feedback from conference participants indicated that the meeting successfully began a dialogue 
through which scientists and insurers can determine how climate forecasts may best be used to benefit themselves and society. Climate scientists gained intellectual support for their work and a clearer understanding of how they can make their forecasts most useful to a business audience. Insurers enhanced their business by learning how they can access more understandable and accurate predictions of future hazards and catastrophes.

The RPI also hosted a series of workshops in 1995. During each workshop, a small group of climate scientists, insurers, and RPI staff met to discuss topics of mutual interest. The first workshop took place at BBSR in February 1995 and concerned the forecasting of the El Niño-Southern Oscillation (ENSO). This is a dominant source of year-to-year variability in global climate, and recent research now allows ENSO forecasts to have usable skill out to $\geq 12$ mo. The ensuing discussion clarified that the insurers were most interested in climate extremes, particularly tropical cyclones, and that the RPI should aim to expand the amount of climate research focused on catastrophic events.

To that end, the second RPI workshop, in March 1995, focused on hurricanes and their prediction. The third RPI workshop, in September 1995, examined a number of statistical approaches to forecasting hurricane frequency and climate variability. The final RPI workshop of 1995 took place at BBSR in December, with the goal of presenting and explicating early forecasts of 1996 Atlantic hurricane activity.

The transfer of climate information and forecasts from scientists to insurers is one goal of the RPI. Equally as important, the RPI aims to help climate scientists recognize and conduct the types of research that insurers find relevant. In 1995 this dialogue generated RPI-initiated and funded research projects at BBSR and at several universities and research institutions in the United States (Table 1).

Dr. T.N. Krishnamurti, a meteorologist at Florida State University, received RPI funding to apply his computer models to studying hurricane behaviors that are directly relevant to insurers. Dr. Krishnamurti and scientists at the Max Planck Institute in Germany have previously used such high-resolution models to simulate individual hurricanes within a computer. trying to understand the physical processes that control their path and intensity. They have also used the models to study how global warming might affect fu-

Table 1

Scientists affiliated with the RPI in 1996

\begin{tabular}{ll}
\hline \multicolumn{1}{c}{ Scientist } & \multicolumn{1}{c}{ Affiliation } \\
\hline Chris Barton & $\begin{array}{l}\text { Center for Coastal Geology } \\
\text { Mark Cunc } \\
\text { Eric Collins }\end{array}$ \\
Scott Cross & Damont Doherty \\
Rosanne D'Arrigo & Duke University \\
Leonard Druyan & Lamont Doherty \\
Jim Elsner & Columbia University \\
Kerry Emanuel & Florida State University \\
& Massachusetts Inst. of \\
David Foster & Technology \\
Isaac Ginis & Harvard University \\
William Gray & University of Rhode Island \\
Tony Knap & Colorado State University \\
T.N. Krishnamurti & Bermuda Biological Station \\
Chris Landsea & Florida State University \\
Kam-biu Liu & NOAA-HRD \\
David Malmquist & Louisiana State University \\
Tony Michacls & Bermuda Biological Station \\
Fid Norton & Bermuda Biological Station \\
Jim O'Brien & Bermuda Biological Station \\
Cecile Penland & Florida State University \\
Dan Schrag & University of Colorado \\
David Scott & Princeton University \\
\hline & Dalhousie University \\
\hline
\end{tabular}

ture hurricane frequency. After discussions with insurers via the RPI, it became clear that these models could also be used to improve hurricane statistics, as one can generate hundreds to thousands of years of hurricane activity within the computer. Insurers can then use the statistical results to build actuarial tables of hurricane recurrence intervals. Currently, insurers must rely on an instrumental record of hurricane activity that at best reaches back 100 years and contains only a few intense storms. The computer models can also be used to investigate how the El Niño-Southern Oscillation and other sources of climate variability may influences hurricane activity. However, to be usable in these contexts, the model must first be able to reproduce observed year-toyear variations in storm frequency and path. Thus the RPI funded Dr. Krishnamurti to run this model using observational data for 1970 to the present to test how accurately it reproduces the observations for those years for all ocean basins.

The RPI also funded Dr. Tim Barnett of the Scripps Institute of Oceanography to analyze how the ENSO affects the frequency of hurricanes and typhoons. In addition, Dr. Tony Michaels of BBSR analyzed the relationship between ENSO and U.S. hurricane landfall. Preliminary results of this work were presented at an RPI workshop in September, and some of the data now reside on the RPI World Wide Web pages.
Based on the insurer interest derived from this early activity, in the second half of 1995, the RPI continued and expanded its direct external funding of climate-related research. Advertised requests for proposals for research grants and postdoctoral fellowships generated an enthusiastic response from climate scientists worldwide. The requests stipulated that the proposed research must help to advance the understanding and prediction of climate variability on time scales of years to decades and explore how climate variability might affect the future frequency, severity, and geographic distribution of catastrophic weather events. Because these proposals encouraged academic research that is relevant to insurers, they were evaluated by both academic peer review and for relevance to insurers' interests. The intent was to sponsor research that can and will be published in peer-reviewed scientific journals (Table 2).

A key question underlying RPI activities has been "What if the past were a poor guide to the future?" Understanding how climate variability influences tropical cyclone activity should enable researchers to more accurately forecast cyclone activity. This is particularly important on an interannual to decadal time scale where insurers make business decisions. It can also be important in determining whether global change will produce hurricane frequencies that differ from the past 50-100 years of instrumental records. Thus the RPI has begun funding projects to investigate past climate variability on time scales of years to decades and to forecast future hurricane frequencies.

Rainfall in the west African Sahel region is one of the key climate features used to forecast Atlantic hurricane frequencies. The relatively low frequency of Atlantic hurricanes in the 1970s and 1980s correlates with a Sahel drought that began around 1970. The return of normal rainfall to the Sahel may presage, or be predictably correlated with a return to the much higher hurricane frequencies of the 1940s and 1950s. However. lack of long-term rainfall data in the Sahel precludes understanding the historical patterns of Sahel drought. To extend rainfall records for the Sahel, scientists will use RPI funding to measure the chemical composition of corals living at the mouth of the Senegal River, which drains the Sahel region. These corals incorporate a salinity signal in their annual growth layers that reflects the input of river water to the ocean. Thus by collecting and analyzing the 
Modeling the effects of hurricanes on continental shelf sediments

The use of oxygen isotopes in cave deposits as proxy records of hurricane generated rainfall

New england historical hurricane reconstruction/poller

Sabel rain/coral project

Multi-year hurricane landfall forecasts

Hurricane general circulation model validation

Seasonal and decadal prediction of Atlantic basin hurricane activity and US landfall probability

The impact of climate change on tropical storm climatology

Trend analysis of hurricane landfalls in the northwest Atlantic Ocean: historic and late holocene occurrences and application to risk analysis

Reconstructing the recurrence intervals of catastrophic hurricanes: lake and marsh sedimentary records from the gulf coast

Reconstructing a 1.000-year record of typhoon activities from chinese historical documentary evidence: A pilot study for guangdong province

Eastern N. American tree ring indices of high-frequency climatic events

A study of Atlantic variability using stochastic and dynamical modeling

Scaling laws and probabilistic forecasting of hurricanes in the Atlantic basin and at landfall locations in Florida. USA

A high-resolution holocene tropical-storm time series, Pedro Bank, northern Nicaraguan rise Effects of El Niño-Southern Oscillation upon Global Tropical Cyclone Activity

Understanding and predicting the effects of large scale climate variability on tropical cycloces: A numerical modeling program
Fielding Norton

David Malmquist

David Foster

Dan Schrag

Jim Elsner

T.N. Krishnamurti

William Gray

Leonard Druyan

David Scott/Eric Collins

Kam-biu Liu

Kam-biu Liu

Rosanne D’Arrigo

Cecile Penland

Chris Barton

Scott Cross

Chris Landsea

Isaac Ginis
BBSR

BBSR

Harvard University

Princeton University

Florida State University

Florida State University

Colorado State University

Columbia University

Dalhousie University

Louisiana State University

Louisiana State University

Lamont Doherty

University of Colorado

Center for Coastal Geology

Duke University

NOAA-HRD

University of Rhode Island corals, a record of Sahel rain spanning several centuries can be constructed.

Another crucial question for insurers is the return period of intense hurricanes and typhoons. Formal records of hurricane activity extend back only 100 years and are truly reliable only since the advent of regular hurricane reconnaissance flights in the 1940s and satellites in the $1960 \mathrm{~s}$. This record is too short for generating accurate estimates of return periods longer than $\sim 20-40$ years for any individual region. To address this problem, RPI-funded scientists are investigating a variety of novel approaches that use paleo-proxy signals and historical data to measure hurricane activity over longer time scales of hundreds to thousands of years. The RPI awards funding for these approaches to research within BBSR and at other institutions.

Beginning in 1996, BBSR scientists will use RPI funds to study the physical relationship between a hurricane and the upper ocean and how a passing hurricane disturbs sediments on continental shelves. Sediment cores taken from continental shelves are expected to record the frequency and severity of past hurricanes. This initial research will be a feasibility project to define the problem and to create a computer model that simulates how a passing hurricane affects the upper ocean, thus helping to identify coastal locations that are most likely to provide samples that record the hurricane signal.
RPI scientists at BBSR and elsewhere will explore two techniques for estimating return periods of land-falling hurricanes. Storm surges associated with intense hurricanes erode sediments from beaches and deposit them in coastal lakes. These deposits are coarser grained than the fine-grained organic materials that normally accumulate there and thus can be readily distinguished as proxy records of a hurricane's passage. Radiocarbon methods allow dating of the storms that generated the layers. Further, the ratio of oxygen isotopes in rain from a hurricane differs significantly from that in rain produced by any other type of storm. Thus hurricane rainfall changes the groundwater isotopic ratio and may affect the ratio incorporated in tree rings and in stalagmites formed in caves. Investigation will start in a variety of cave environments, starting in Bermuda. Bermuda has an excellent historical record of hurricane landfall, which can be used to calibrate these two approaches for the period 1609 to the present.

The RPI is also funding a project to extend the published record of observed historical storms in China, New England, and elsewhere. We have initiated a program with scientists from China to make their very long historical records available to scientists in the West. An existing study of hurricanes in New England back to the mid-1600s conducted by scientists at the Harvard Forest will be made available through RPI funding.

During 1995 and early 1996. the science and business communities' interest in the RPI continued to grow. Much of the success is due to the interaction that Bermuda affords, a strong science base at the Bermuda Biological Station for Research, Inc., and the need and input of international insurance and reinsurance companies. One interesting spin-off from the program is that the insurers now see a need to hire ocean and climate scientists to both interact with the RPI on behalf of the insurers and to develop specialized tools in their own companies to use the science that they now understand. Therefore, if any readers of this article have an interest in working as a scientist for an international catestrophic reinsurer. they should contact the authors of this article for more information. The expanded interactions between this science community and the insurance industry provides job opportunities, a greater understanding of the value of science, and potentially a more effective societal response to the disasters that occur when strong tropical cyclones make landfall.

For more information about International Policy Issues, please contact Anne Arquit Niederberger, editor, International Policy Issues column, Forum for Climate and Global Change, Swiss Academy of Sciences. Baerenplatz 2, CH-3011 Bern, Switzerland. Internet: arquit@sanw.unibe.ch. 